EstAg 34 / fasc. 3 (1999) 577-601

\title{
La estructura dinámica de la realidad en Zubiri
}

\section{Introducción}

Tras la publicación de su famoso libro Sobre la esencia, Zubiri recibió diversas críticas a su obra. Principalmente se le acusaba de ofrecer una visión estática y conceptualista de la realidad. Zubiri rechaza de plano esta imputación y responde a ella con una serie de estudios sobre la Estructura dinámica de la realidad cuya tesis principal puede resumirse así: «La realidad como esencia es una estructura. Una estructura constitutiva, pero cuyos momentos y cuyos ingredientes de constitución son activos y dinámicos por sí mismos. Por consiguiente, es absolutamente quimérico lo que se ha dicho algunas veces de mi libro. Se ha dicho que es un libro estático, y un libro puramente quiescente y de conceptos. Lo siento mucho. Tendré o no tendré razón, pero estimo precisamente que el dinamismo compete esencial y formalmente a la esencia tal como la he descrito en mi modesto y pesado libro Sobre la esencia» ${ }^{1}$. A continuación presentamos algunas claves de esa segunda obra.

\section{El problema de la realidad dinámica}

«La realidad no es solamente lo que es actualmente; también está, en una $u$ otra forma, incursa en eso que de una manera más o menos vaga podemos llamar devenir. Las cosas devienen, la realidad deviene» ${ }^{2}$. La realidad no es "en sí" ni "para sî" sino que es "de suyo" y "da de si".

1. X. ZuBIRI, Estructura dinámica de la realidad. Alianza. Fundación Zubiri. Madrid 1995, $2^{\mathrm{a}}$, iii. En adelante EDR. Para tener una idea sustantiva del escrito Sobre la esencia puede verse: D. NATAL, Sobre el ser y la esencia en Zubiri, en Est. Agust. 32 (1997) 71-85.

2. EDR iv 
Devenir es «llegar a ser algo, pero inexorablemente dejando de ser algo que se era, o añadiendo algo que no se era a lo que ya es, a lo que ya era» ${ }^{3}$. El devenir está constituido por "un momento de no-ser" mientras que las cosas "están constituidas nada más que por el momento del ser". El devenir es una articulación interna, "intrínseca, entre eso que llamamos ser y eso que llamamos no-ser". La filosofía da razón de esta articulación, entre el ser que es y del no-ser que no es. «Parménides rechaza el no-ser como algo que no es, y por consiguiente rechaza el devenir. Y esto es esencial en el problema» ${ }^{4}$. Así crea un ser "inmóvil".

A su vez, «el "no-ser" no es una especie de nada que flota por ahí de una manera vaga». «El ser sería la mismidad, y el no-ser, la alteridad. En definitiva, entonces -dirá Platón- el movimiento participa del ser y del no-ser» 5. Para Aristóteles el movimiento no es paso del ser al no ser y viceversa sino que es "más bien un pasar de una manera de ser a otra. Dejar de ser y adquirir el ser: llegar a ser". Para A. se trata de la articulación física de una cosa, del problema del cambio: El devenir es cambio y "cambiar envuelve justamente un momento de no-ser".

El problema del cambio, en Aristóteles, por muy físico que sea, envuelve el ser y el no ser y su genialidad consiste «en haber acuñado conceptos como el de dynamis, de potencia, para alumbrar con ellos dimensiones metafísicas inmensas de la realidad» 6. En cualquier caso el problema del devenir es "un problema de ser". Además, el que es y no es en el devenir es un sujeto, y este devenir "consiste en cambiar".

\section{La experiencia del ser en la realidad}

En la concepción clásica, la realidad es un adjetivo del ser: "La realidad es un momento y un modo del ser; lo que prima es justamente el esse, el ser". Para Zubiri "el ser es la actualidad de la realidad", es el ser de la realidad. Primero tenemos la luminaria, la realidad, luego la luz, el ser, «y tenemos la luz en tanto que revertiendo sobre la propia luminaria de la cual emerge, el ser revertiendo sobre la realidad. Esta reversión es precisamente lo que constituye el ser de lo sustantivo» 7 .

3. EDR 11.

4. EDR 13.

5. EDR 15

6. EDR 17.

7. EDR 27. 


\subsection{Realidad y estructura}

El ser es realitas in essendo, no el esse reale. Así la realidad constitutiva "de suyo", con todas sus notas necesarias y suficientes como realidad sustantiva, es la que fundamenta el ser y "es justamente lo que he llamado esencia", o "unidad coherencial primaria". "La realidad es radical y primariamente no subjetualidad sino estructuralidad. Es estructura. Estructura es la actualidad de la unidad primaria en un sistema constructo de notas» ${ }^{8}$. Del mismo modo: "El organismo no es sustancia, es justamente estructura". Y su "constitución es el modo como algo es uno".

El devenir afecta directamente a la realidad y no al ser. La realidad "es precisamente una sustantividad que está dotada de una estructura, y de un sistema constructo de notas". Para Aristóteles, el ser es substancia (hypo-keimenon), una physis y una dynamis (potencia), no un keimenon, "lo que está ahí", como para Parménides. El acto es enérgeia. El movimiento es la potencia actuando como tal potencia, «sin haber terminado de producir todo su efecto. Entonces es cuando la sustancia es móvil» ${ }^{9}$.

El movimiento "no consiste ni en poder ni en ser, sino en estar pudiendo". «Es la célebre definición de Aristóteles: El acto de la potencia del ente en cuanto tal, es decir, en cuanto tal potencia. $H$ tou dynámei óntos entelejeia, $n$ toiouton" 10 . La idea de la dynamis "es uno de los conceptos grandiosos y geniales que se han producido en la historia de la Filosofía".

El Mundo no es un compuesto de sustancias previas ajustadas después, unas a otras, sino que primero es el campo del Universo y luego son las cosas: «Las cosas concretas, las cosas reales materiales, son los puntos de aplicación del campo» ${ }^{11}$. Así el campo es un proceso que sigue sus propias leyes y así da lugar al cambio. "El dinamismo sería procesualidad", no simplemente cambio. Y el Universo sería profundamente "dinámico en sí mismo".

Entonces, «la realidad es una sustantividad que está esencial y estructuralmente en condición de respectividad» 12 . Toda realidad es constitutivamente respectiva. Y así constituye el Cosmos en su talidad, en su ser como tal. La respectividad de lo real es "aquello en virtud de lo cual la realidad justamente es algo de suyo", o si se prefiere la realidad "de suyo es intrínseca y formalmente respectiva". La respectividad es "una dimensión física de las cosas", es algo "físico en el sentido tradicional y filosófico del vocablo".
8. EDR 37
9. EDR 46.
10. EDR 47.
11. EDR 52.
12. EDR 56. 


\section{La realidad como dinamismo y cambio}

«Las cosas, precisamente porque son de suyo, tienen un momento activo que consiste en dar de sí. Y este dar de sí es la expresión misma de su actividad»13. Así la dynamis o potencia no brota de la realidad «sino que "es" la constitución misma de la realidad en cuanto realidad». Toda realidad es activa por ser real. Esto es lo que llama Zubiri dinamismo: "Es la realidad en su constitutivo dar de sí”. «La dynamis no es nada distinto de la realidad; es la realidad misma en tanto que real, pura y simplemente» ${ }^{14}$. Y "ese dar de sí no es algo distinto de la realidad misma en la cual las cosas son constitutivamente lo que son".

El cambio no es lo que constituye el dinamismo sino el modo en el que la realidad que da de sí acontece. "El dinamismo no es otra cosa, sino la realidad en su dar de sí". La misma realidad es en sí misma "constitutiva y constitucionalmente dinamismo". El proceso es la expresión de ese dinamismo. El mundo es un dinamismo que no consiste en su carácter procesual sino en su dar de sí y esto no es otra cosa que "estar siendo lo que efectivamente ya se es". El dinamismo es constitutivo del mundo. El mundo consiste en dar de sí y este dar de sí "es justamente el dinamismo".

Por tanto la realidad es la que deviene con todas sus estructuras y su dinamismo. Son estructuras de actividad y esa realidad es dinámica por sí misma. La realidad es lo que es instantáneamente "y todo aquello que puede dar de sí". Ahora bien, en su dinamismo, "la realidad es causal": «Me sitúo, pues, en el punto de vista de la causalidad, interpretando el dinamismo como un dinamismo causal» 15 .

\section{El dinamismo causal de la realidad}

Aristóteles dice: "principio consiste en que algo proceda de otro", aquello de donde procede algo eso es justamente principio. «La causa -aitía- "es un modo de principio". Y no dice más». Se dice que causa es aquello "ex ou" de donde algo deviene, procede, y está en el fondo de su ser "como el bronce respecto de la estatua, o la plata respecto de la joya", es la causa material ${ }^{16}$. Además la causa es justamente el eidos, la causa formal, "la razón de que algo

13. EDR 61.

14. EDR 61.

15. EDR 67.

16. EDR 72. 
sea lo que es". Por otra parte, es causa la causa eficiente o que hace algo, y también la causa final o el fin para el que se hace algo ${ }^{17}$.

Aristóteles no dice qué tienen en común las cuatro causas. Sí dice que "las causas son principios". La causa final es propia de las cosas humanas, la causalidad material y formal casi han desaparecido y sólo queda la causalidad eficiente. Esta es le principio primero de transformación "el principio primero del movimiento o del reposo de algo". Ha tenido gran influencia en la historia del pensamiento.

Galileo cambia la teoría de la causalidad y la orienta a explicar cómo suceden las cosas, "cómo acontecen los movimientos del Universo". Ya no se trata propiamente de la causalidad sino de "un problema de ley". En Newton la ley es una relación de la masa con la fuerza y la aceleración. Hume critica el concepto de ley y la idea de causalidad, para él es un puro concepto como "la idea de un hábito o costumbre", una simple belief, "cosa que a Kant le parece irresistible". Para él, la idea de causa, de algo distinto de lo que acontece «jamás podrá obtenerse del análisis del concepto de aquello que acontece» 18 .

Para Kant la causalidad es un "puro principio de conocimiento" que no se funda en un análisis de los conceptos o de la realidad sino que "es una condición de inteligibilidad propia del intelecto humano", porque debe tener un valor absoluto. La ciencia no tendría propiamente que ver con la causalidad: "La ciencia sólo trata de explicar cómo ocurren las cosas". Ahí todo es determinismo porque todo está determinado por sus antecedentes según unas regularidades. Muchas realidades escapan a ese determinismo, pero "en conjunto hay un determinismo estadístico sobre el cual están fundadas las Ciencias de la Realidad".

Y sin embargo, la realidad no es determinista en la ciencia actual. Muchos científicos defienden el determinismo. «Pero los creadores de la Mecánica del átomo no lo han creído nunca: Ni Einstein, ni Dirac, ni Schrödinger, ni Planck» 19. Eso se lo dijo el mismo Planck a Zubiri. Así hoy "el indeterminismo de las partículas elementales es absolutamente innegable".

En resumen, la causa material es un principio intrínseco al deviniente, la formal una determinación o definición, la eficiente un principio de transformación y la final un telos o terminación ${ }^{20}$. La visión del mundo desde el efecto es determinista pero ¿cómo sería desde la causa?. El Cosmos quizá sea

17. EDR 73.

18. EDR 77.

19. EDR 80.

20. EDR 81. 
efectivamente así, en ocasiones, como pensaba Laplace, pero "podía tal vez haber sido de otra manera" 21.

Dice Zubiri: «La causalidad, a mi modo de ver, es pura y simplemente la funcionalidad de lo real en tanto que real» 22 . El hombre no percibe sólo tales y cuales cosas concretas de "lo que es real, sino que es real": «La impresión de realidad forma parte de la percepción" 23. "Y lo que se llama causa tiene alguna influencia sobre la realidad del efecto. Es la influencia de lo real en tanto que real".

El dar de sí determina la actividad y por su actuosidad, en la respectividad, interna y externa, las cosas componen el mundo y su función de causa. Esa actividad "en tanto que determinante de cuanto en ello acontece, es justamente la causalidad". Así, «el dinamismo del mundo es un dinamismo intrínseca y formalmente causal» ${ }^{24}$. La causalidad es "precisamente determinación" no determinismo. «Causalidad es determinación de lo real en la actividad del todo» 25 .

Por tanto la causalidad se encuentra "en el todo en cuanto tal", es "una condición de lo real en tanto que real" con "carácter necesario". No se deben confundir las causas con las condiciones. La ciencia no se ocupa de esas distinciones porque sólo busca cómo acontecen las cosas. Las condiciones no son causalidad pero manifiestan la causalidad que ejerce el Universo entero como proceso en cada fenómeno concreto. La legalidad científica "no es la causalidad, pero expresa la causalidad". «La realidad, en su radical unidad, es por esto dinamismo causal» 26. Causalidad es "la funcionalidad de lo real en tanto que real”, en cuanto es de suyo y da de sí: «Este dar de sí en funcionalidad de lo real en tanto que real es justamente la causalidad» 27.

Según Zubiri, todo acto libre está rigurosamente determinado por todos sus antecedentes pero no por eso deja de ser libre, pues esos antecedentes los pone, en buena parte, el sujeto y así se sale del esquema "antecedente-consecuente" sin más. Por lo demás «el Determinismo es a lo sumo un esquema de un tipo especial de causalidad, pero no es la causalidad en sí misma» 28 . El hombre es un ser abierto. «La apertura de la esencia abierta no está añadida a las estructuras en virtud de las cuales esta esencia es algo en sí» 29.

21. EDR 94.cf. M. CAPEK, El impacto filosófico de la física contemporánea. Madrid 1965, 361.

22. EDR 84

23. EDR 83

24. EDR 88,99

25. EDR 91

26. EDR 97

27. EDR 97

28. EDR 99

29. EDR 102 
La diferencia entre esencias abiertas y cerradas es el punto de apoyo para ver "los distintos tipos de dinamismo causal que existen en el Universo", pues los dinamismos son los distintos "modos de dar de sí que tienen las sustantividades por razón de su estructura esencial". Cuando más se sube en la escala de realidades se encuentra más devenir y menos variación. «Cuanto más rica sea la sustantividad, tanto más da de sí y tanto menos cambia. Pero esto no quiere decir que el cambio no sea justamente el dinamismo básico de todos los demás dinamismos» 30 .

\section{La realidad y su dinamismo de variación}

La realidad no es sustancia sino sustantividad y «sustantividad quiere decir ser un sistema de notas suficientes en el orden de la constitución. De ahí que estas notas no son rigurosamente inherentes. Pues la res a quien serían inherentes no es un subjectum» 31 . Esas notas expresan el aspecto irreductible de la respectividad "en que se encuentran instituidas en la realidad las realidades sustantivas", pues hay un dar de sí en la sustantividad que concierne a su capacidad para "tener distintas notas adherentes". En ese sentido, dar de sí "significa prefijar" lo que "adherentemente puede ser una realidad sustantiva". El mero cambio es un dar de sí mínimo y la menor de las causalidades. Así distinguimos: "el movimiento local, el movimiento cuantitativo y el movimiento cualitativo".

El cambio de lugar no es un mero "cambio de carácter mecánico". El mismo campo electromagnético es "un campo irreductible a un movimiento mecánico". Del mismo modo la estructuras físico-químicas incluyen el movimiento local. El crecimiento de la realidad no es un mero "desplazamiento"; aunque no hay crecimiento sin desplazamiento. "El lugar es esencial, constitutiva y formalmente respectivo; si empleo la palabra respectivo es, en este sentido, respectivo a los lugares de las demás cosas". En todo caso, el dinamismo variacional se funda en "la totalidad de la respectividad" del Universo.

«El espacio es la respectividad de las cosas reales por razón del lugar ocupado por ellas» 32 . Zubiri insiste en la ocupación, la realidad y la respectividad. Y en la estructura topológica del espacio como el "estar junto a". La "dirección hacia" es la afinidad y el paralelismo. El colocar un cuerpo a distancia respectiva de otro "implica una afinidad determinada", una "topología

30. EDR 104.

31. EDR 105.

32. EDR 113 
absolutamente determinada". El moverse unas cosas entre otras es el espacio como libre juego de movimientos mecánicos y locales. La luz y su velocidad límite, la gravedad y su curvatura, y la acción, son las claves de la mecánica cuántica y de "la estructura física del espacio".

Para Aristóteles el movimiento es "la actualidad de la potencia en tanto que potencia, es decir, acto imperfecto, como él decía, atelés", sin acabar. Pero esto no es nada claro. El movimiento es siempre respectividad de un móvil respecto de otros. No existe el espacio absoluto. «El espacio es la respectividad de unos cuerpos con otros. El movimiento envuelve esencial y constitutivamente una relatividad, un principio de relatividad» ${ }^{33}$, aunque el movimiento tenga un carácter absoluto, pues "el Universo entero está en movimiento" y su estructura es dinámica de por sí. Así la gravitación en Einstein es una fuerza como la inercia es "una estructura del espacio" como en Newton "la fuerza es el producto de la masa por la aceleración".

Einstein relativizó "por completo el concepto de fuerza", pues la fuerza no produce el campo: «La fuerza no tiene carácter causal. La gravitación es una estructura: la curvatura del Universo. No existe para Einstein fuerza de gravitación. Ni remotamente» 34 . El movimiento del Universo no se origina en las cosas: «El Universo está en movimiento en y por sí mismo. No hay nadie ni nada que haya desencadenado el movimiento en el Universo» 35. Como mucho se puede decir que la "respectividad integral" es la causa del dinamismo. La causa del movimiento "es pura y simplemente la índole activa de la realidad", "ni más ni menos, ni menos ni más". Todo cuerpo es activo por ser respectivo a "las demás sustantividades del Universo".

$\mathrm{El}$ "movimiento radical es el cambio de lugar". El tiempo afecta directamente a la actualidad de las cosas, no a su realidad. El tiempo es un modo de ser del movimiento pero no constituye formalmente el movimiento. $\mathrm{La}$ reversión del tiempo es un tema muy obscuro, ni Heisenberg lo explicaba bien. La cronología y la cronometría son estructuras del tiempo como actualidad del "dinamismo real y físico espacial de los cuerpos". El movimiento no tiene porqué ser mecánico, pues es respectividad.

«El mundo está real y constitutivamente en movimiento» ${ }^{36}$. Por eso se mueve en cada una de las cosas, desde su "dar de sí", desde su constitutiva respectividad "en que están todas las realidades del Universo". No se trata de que la realidad sea actividad como en Leibniz. "La realidad es activa por sí misma", reposa en su sustantividad y su esencia es "la realidad simpliciter de

33. EDR 117.

34. EDR 120.

35. EDR 121.

36. EDR 125. 
las cosas en el mundo". Esas cosas a las que les "es esencial estar en alguna parte". Los cambios de lugar son otros tantos momentos, de "un dar de sí de las cosas".

\subsection{La realidad en su dinamismo de alteración}

Todas las realidades, en sus esencias constitutivas, son "activas por sí mismas" y al dar de sí desarrollan sus acciones. Aquí importa «el substrato inmediato sobre el que se apoya una esencia constitutiva para poder emerger en el Universo» 37. Cada substrato está inmerso en una configuración que le es esencial. Pero ahora ya no hablamos del cambio como variación sino como alteración. Este es "un dar de sí, en el que lo que se da de sí es justamente un alter, otro". Así, hablamos de transformación cuando una sustantividad se convierte en otra, aunque no sea fácil de admitir, como en la generación.

En el mixto, los elementos que lo producen no están allí actualmente, "están nada más virtualmente" como presencia actual o como presencia virtual según las distintas teorías. Zubiri piensa que ni lo uno ni lo otro pues la transformación da lugar "a propiedades sistemáticas nuevas". Son propiedades sistemáticas nuevas que no se pueden distribuir entre cada una de las partes del sistema. Se trata de una transformación estructural y no consiste en que una sustancia tome formas sustanciales diferentes sino «en que una estructura, ella, desde sí misma, en tanto que estructura, dé lugar desde sí a una estructura completamente distinta» 38 .

«El dinamismo de repetición es un momento del dinamismo de transformación. Y el resultado de esta repetición es enormemente importante. Porque la repetición lo que produce es una multiplicidad de elementos que son iguales» ${ }^{39}$, sin excluir la singularidad. En este dinamismo hay menos cambio que en el de transformación. Hay también el dinamismo de la producción de la especie y la génesis o evolución. Para que sea realmente multiplicación se necesita que sea paradigmática de modo que los productores o las sustantividades productoras de la génesis "sean en una o en otra medida paradigmas que se conservan y se perpetúan a través de las sustantividades efectadas" 40 .

A eso Zubiri le llamaría un phylum pues se trata "justamente de una línea homónima, y de carácter paradigmático", en la que "la sustantividad hija, no sería lo que es sino en tanto en cuanto pertenece a un phylum determinado".

37. EDR 131.

38. EDR 139.

39. EDR 141.

40. EDR 143 
Este es "el dinamismo de la especiación", por el que se trasmite constitutivamente "la esencia filial". Se trata de una acción constituyente no de la simple trasmisión. Y esa acción constituyente es generante "en la medida en que las sustantividades son las que formalmente van constituyendo la realidad de su efecto". Los progenitores ofrecen un esquema constituyente al generado que sirve a la constitución de su esencia constituyente. La sustantividad de los padres, da de sí sus potencialidades de constitución.

El dinamismo causal da de sí una nueva sustantividad "una nueva esencia constitutiva". La evolución es "la capacidad de integrar la mutación". La evolución no está en la transformación sino «en el momento de dar de sí bajo la forma de integración de la mutación» 41. La evolución es "la actualidad de las potencialidades", no sólo virtualidad y actualidad. Es como una génesis del "de suyo".

La evolución creadora no es el élan vital sino un choque de estructuras y la evolución está precisamente "en integrar esa mutación". No se trata de un impulso vital sino de una potencialidades evolutivas de la realidad en nueva configuración. Cada esencia tiene un sistema muy preciso y determinado de potencialidades «que solamente de una manera estructural, y a lo largo del tiempo, y a lo largo del dinamismo se van actualizando» 42 . El logro de la evolución es una taxis y una individuación de individuos constituidos en especies.

Del mismo modo, la producción de ciertos tipos de Espacio es un logro de la evolución. Se dan distintas posibilidades y probabilidades expresadas en una serie de leyes, con cierta uniformidad estadística, desde unas constantes universales como las de la mecánica cuántica, que también son "producto de la evolución". Así la realidad es "estructuralmente emergente" y da de sí una alteridad.

Se suele decir que en la línea del ser no cabe evolución, pero, según Zubiri, en la línea de la realidad sí. Por ejemplo, el "de suyo" de un orangután es inferior al del hombre o al de Dios. La realidad es evolvente por su propia estructura. La sustantividad es siempre activa con la triple posibilidad de transformación, repetición y generación. "Cada una de estas dimensiones está constitutivamente apoyada en la anterior".

\subsection{La realidad en su dinamismo de mismidad}

La realidad es activa por sí misma. Y este dinamismo causal constituye la funcionalidad de lo real en tanto que real, en la respectividad, y lleva a la variación y la alteración. Así hay transformación, generación y evolución. Esta es la

41. EDR 147.

42. EDR 151. 
alteración visible. La pura mutación no es evolución, sí lo es su integración. La generación actualiza virtualidades, la evolución nuevas potencialidades. El devenir que produce nuevas formas «"del de sí" del "de suyo"» es "estrictamente metafísico". Se trata de un dinamismo metafísico en virtud del cual nuevos grados superiores emergen de los inferiores con una estabilidad "sustantiva".

La primera es la "sustantividad molecular" con cierta persistencia estructural que lleva consigo cierta estabilidad de los átomos y las moléculas y formaciones moleculares estables como el agua, el hierro, etc. Hay también la sustantividad estructural característica del ser vivo que no es molecular sino transmolecular. El ser vivo es un sistema de moléculas, ejerce una enorme actividad, adquiere cierta independencia y persiste «en su propia sustantividad, en su propia identidad sustantiva. $Y$ esto es justamente lo propio de la estructura viva» 43.

Se trata como siempre de una respectividad sustantiva en equilibrio dinámico, no es una sustancia más ni una super-sustancia sino que "es una estructura dinámica", con unas estructuras básicas siempre en proceso, un topos y un situs. El viviente no sólo ocupa un lugar sino que está en un medio como "en un centro suyo" y tiene una orientación, un "espacio vital" y un tiempo con "cierta edad" y periodicidad. Los seres vivientes juntos tienen una "estructura ecológica esencial en la Biología" y "sobre todo en la evolución". Los vivientes forman una asociación y disponen de un aislamiento muy importante en su evolución. Además tienen un "misterioso pero innegable factor que es la dispersión. La vida se difunde y se dispersa por todo el Planeta".

El viviente cambia constantemente "para poder seguir siendo igual que lo era antes". Se trata de un nuevo dar de sí: "Es responder adecuadamente". "Cada organismo tiene un poco su norma de reacción", a partir de una incitación que orienta la tensión vital hacia una respuesta. Sin esa incitación el vivente moriría. "La estructura suscitación - respuesta" es esencial al ser vivo que tiene una "habitud" o modo habitual de vérselas con las cosas y sus solicitaciones de alimento, estimulación, etc.

El ser vivo se relaciona de modo permanente con su medio para «persistir en su estructura. Y esta estructura, radical y fundamental, es la que constituye la estructura sustantiva de un ser vivo» ${ }^{44}$. Cada ser vivo y su sistema es una innovación "respecto de las propiedades que lo componen". La vida consiste en un sistema de actividades "para mantener unas sustantividades, y esas actividades tienen una dimensión esencial, constitutivamente evolutiva".

Frente a la estabilización de la materia en partículas o moléculas, más o

43. EDR 165.

44. EDR 175. 
menos estables, en los seres vivos tenemos "algo que, repito, yo llamaría la vitalización de la materia. $Y$ esta vitalización de la materia justamente da lugar a una marcha progresiva". Además esa materia viva se organiza en un núcleo, código genético etc. Eso es "la interiorización de la vida" concentrada "en un punto nuclear" "rector de las manifestaciones fundamentales de la vida".

El ser vivo es individuo y es parte de la especie. «En el caso del organismo pluricelular hay una disociación radical y esencial entre la suerte del individuo y la suerte de la especie» 45. Ambas suertes se vinculan "a la asociación con otros seres vivos, $y$, sobre todo, en la forma más íntima de posesión" en la reproducción sexual.

La sensibilidad animal es el primer nivel del psiquismo. Es justamente el momento en que se produce, de una u otra forma, la animalización de la vida, en la que aparece "la función de sentir de una manera temática". Esas funciones, en un momento determinado, se centralizan: «Es la centralización del sentir, la centralización de la vida animal. Lo cual es enormemente importante. Pensemos que por esto a un animal, en general, se le puede dar la puntilla, cosa que no se puede hacer con ningún vegetal» 46 . Un vegetal no está centralizado, pero el animal cuanto más se supera más se centra hasta llegar al hombre capaz de decir: "me siento hambriento", "me siento sediento".

Además de la centralización hay, en el animal, un equilibrio interno $\mathrm{u}$ homeóstasis, un equilibrio dinámico que progresa en diversas fases y diferentes funciones superiores e inferiores. En el animal hay además una corticalización: «Se va constituyendo no solamente un eje central sino que ese eje central termina en un telencéfalo, y el telencéfalo culmina justamente en una corteza» ${ }^{47}$. Así, el cangrejo no reconoce su presa sin su contexto, en cambio, el animal superior ve la presa recortada, independiente de lo demás, es lo que llama Zubiri formalización, y aprende situaciones cada vez más ricas y variadas así como nuevas conductas.

Conducta y formalización se complementan. Así desde la interiorización de la materia a la máxima formalización en la corticalización, la interiorización es cada vez mayor en el ser vivo. Toda realidad tiene interioridad: «Toda realidad, por serlo, tiene un intus, que se manifiesta en un ex, que es precisamente el sistema de notas estructurales en que consiste la esencia de su sustantividad» 48 . Esta interiorización de los seres vivos constituye su "mismi-

45. EDR 179.

46. EDR 181.

47. EDR 182.

48. EDR 183-4. 
dad". La "mismidad como forma de realidad" es "lo esencial de un ser vivo".

No se trata sólo de aguantar las vicisitudes recibidas de fuera en medio de sus actividades sino que las ejercita para poder ser el mismo. "La mismidad es esencial y formalmente un acto de poseerse". No estamos ante una acción reflexiva sino que la totalidad del propio ser se envuelve en las actividades que hace para perseverar en su ser. "La vida es justamente un poseerse". Esa es la marcha de la vida "misma" y "autoposesiva". Por tanto la vida no es ni el aliento vital, ni pura espontaneidad, ni basta decir que las actividades del ser vivo "son inmanentes".

La esencia de la vida consiste entonces no en ser sujeto in sino en ser una actividad por sí misma, "la estructura activa por sí misma en orden justamente a dar de sí de su propia mismidad": «El viviente es aquella realidad, cuya forma de realidad consiste en darse a sí propio su propia mismidad» ${ }^{49}$. El ser vivo se renueva para ser sí mismo, para ser "más sí mismo" y para "darse entero a otro" v. gr. en el amor. Así el ser vivo es una estructura no una sustancia.

Para Hegel y Fichte la vida es identidad. Pero el sí mismo no es "un resultado de la vida sino un principio de ella". El sí mismo no consiste en ser sujeto ni identidad sino "en ser siempre el mismo" en una mismidad dinámica. El ser viviente es «"de suyo" el mismo» . «Vivir no es sino esto: ser reduplicativa y formalmente sí mismo, es decir, ser estructuralmente el mismo» 50.

La vida es poseerse, "ejecutar formalmente su mismidad" y poseerse fluyentemente. Esa actividad es una respuesta adecuada desde sí mismo y para sí mismo, y mantener el equilibrio de su mismidad en el cambio: «Vivir es fluir para ser el mismo» 51 . El viviente es aquel ser que sólo puede ser el mismo "no siendo jamás lo mismo". Eso es dar de sí adecuadamente. En la escala de los seres, estos se construyen poco a poco "un mayor de suyo" y con ello "una mayor sustantividad". La vida es un deviniente "dar de sí de la mismidad", pero la vida, aún en su niveles más perfectos, "no pasa de ser un primordium de lo que es precisamente la plena y la formal mismidad".

Tal es el proceso de la vida desde la constitución de la materia viva a la corticalización o formalización creadora. El viviente es la realidad cuyas estructuras dan de sí mismas dinámicamente, y cuando el de suyo se hace mismo «el dar de sí consiste en mismidad, por su propia mismidad. Pero cuando el de suyo se hace plenario, lo cual acontece en la esencia abierta, es decir, en el hombre, entonces el dinamismo sube de grado» 52 .

49. EDR 188

50. EDR 198.

51. EDR 199.

52. EDR 204 


\subsection{El dinamismo de la realidad en la suidad}

Cuando el animal no sólo recibe incitaciones y da respuestas sino que se hace cargo de la realidad encontramos al hombre: «La hiperformalización constituye precisamente al animal que se hace cargo de la realidad, de modo que pueda continuar la estabilidad de la especie» 53. Ahí las cosas ya no son mero estímulo, sino algo "de suyo", que se presenta como verdadera realidad, no como medio sino como mundo. El hombre es una esencia abierta a la realidad de las cosas: «Estructuralmente, el hombre -digo- es un animal de realidades» 54 . La realidad no es sólo algo que funciona en la vida sino "algo para lo que la vida está funcionando".

Abierta a sí misma, la realidad del hombre no sólo es de suyo sino que consiste en ser "suya". «Y el ser suyo es justamente lo que llamamos persona» (...). «Esta es la verdadera sustantividad, la radical sustantividad. El hombre es estructuralmente animal de realidades; modalmente es una realidad "suya": persona» 55. La persona es una esencia abierta, sobre todo, a su propia realidad y en ella a las demás cosas "en tanto que reales". Esa apertura no es algo secundario: «Sino que la apertura es una modificación estructural de estructuras que en sí mismas posee el ser humano, la realidad humana» 56.

«La inteligencia es una nota de lo que el hombre es "en sî", pero en función transcendental esta nota nos abre al todo de la realidad qua realidad» 57 . Y esa apertura constituye un modo del en sí. La personización es un paso de la mismidad a la suidad. El hombre ha evolucionado en dos millones de años. Los pasos de la evolución se dan en tipos intrínsecamente diferentes de hombre. Cada uno es transformación del anterior por una estricta evolución del psiquismo animal al humano.

El hombre es animal de inteligencia o sea un animal de realidades. Y la inteligencia es un factor biológico de estabilización y respuesta adecuada en cada individuo. Estamos ante un dinamismo nuevo del todo, una gran innovación, más allá de la realidad-estímulo. Es también una causalidad nueva que produce la inteligencia y el psiquismo humano. No obstante el hombre y su inteligencia es un momento del "dinamismo del Todo y de la naturaleza naturans" desde la evolución animal.

"El origen de las esencias abiertas está en el Todo" y son "modificación de las esencias cerradas" con una nueva respectividad, "en apertura" a la rea-

53. EDR 206.

54. EDR 206.

55. EDR 207.

56. EDR 207.

57. EDR 208. 
lidad, que acontece en cada persona en su personización de la vida. Así la vida se hace hiperformalizada, y por tanto hiper-misma. De este modo el hombre se hace cargo de la realidad en cuanto tal. No es que sea un "metafísico ambulante", pero por su inteligencia se convierte en una "animal de realidades" con una "esencia nueva" y una "innovación cualitativa".

Entre esa esencia humana con inteligencia y la animal hay "una esencial diferencia". Al principio la realidad es estimulante pero "el hombre está abierto al carácter de realidad". Lo primero a lo que está abierta la esencia inteligente es a su propio carácter de realidad y así se abre al carácter de la realidad en cuanto tal. Está colocado entre las cosas, como los animales, pero «donde está colocado, y a la vez instalado, es en la realidad» 58 . Su medio "es un mundo, es decir: un sistema de realidades en tanto que realidades".

Ahora poseerse ya no es sólo continuar vivo, como el animal, "sino que es ser su propia realidad. La sustantividad humana es eo ipso persona", es de suyo y suya y se conserva en su suidad. De la mismidad ha pasado a la suidad. Tiene un me personal del que carece el animal, v. gr. "me he dado un paseo", y se siente el centro de las cosas como mi o se enfrenta a ellas como un yo distinto. Así, en su actividad reactualiza su persona. Esa reactualización es el ser de la realidad sustantiva que consiste en revertir por identidad a la realidad. «Y esa reversión en identidad es lo que metafísicamente he llamado la intimidad» 59. En esa interiorización consiste la persona. Su acción es un momento de su ser sustantivo, y su poseerse es un hacerse persona en cada instante.

$\mathrm{Su}$ ser con las cosas, con los otros hombres y consigo mismo, es "un momento intrínseco y formal de la estructura de la vida", de mí mismo y del dinamismo humano como tal. Esencial y constitutivamente la vida es vida con... las cosas como realidad y como sentido: «El sentido es el constructo de la realidad con la vida humana» 60 . Pero el sentido se funda "en la capacidad que tiene la realidad para estar constituida en sentido" y dar posibilidades.

"La posibilidad es algo radical", "de hacer tal o cual cosa en tanto que real". Esa es la posibilidad "dentro de la cual puede haber finalidad y mediación". Así el acto "es acto de una potencia". Pero existe también la acción que se compone "de todas las funciones y de todos los actos": "Las posibilidades son posibilidades para unas acciones propias y enteras de la sustantividad en cuanto tal". Y la posibilidad "es precisamente la propia sustantividad y su situación como recurso para sus acciones". Los recursos son las cosas y las propias dotes de mi sustantividad: «Aquí no es dynamis para el acto o función,

58. EDR 221.

59. EDR 224.

60. EDR 228. 
sino que es mi propia sustantividad personal como recurso de mi personalidad» 61 .

La fuerza que imponen al hombre las posibilidades, los recursos, es el poder. Este no es una mera causa eficiente más, sino: "la dominancia de la realidad en tanto que realidad". No se trata de una mera fuerza, pues «el poder de todos los poderes es justamente el poder de lo real en tanto que real» 62 . El hombre, movido por este poder que insta a actuar, se apropia unas posibilidades y rechaza otras. "El hombre tiene poder y está constitutivamente apoderado por aquello que hace". La personalización es "el apoderamiento de las posibilidades".

Así "que la personalización no deja fuera de sí a las estructuras sino que las absorbe en su mismidad". Toda posibilidad es un proyecto incoado, y toda realización es un evento que no puede ser realmente "sino pasando por el rodeo de la irrealidad", pues él mismo produce "la posibilidad de la realidad antes que producir la realidad". Justamente, en eso, es el hombre cuasi-creador: «El dinamismo de la suidad es el dinamismo constitutivo de la posibilidad en cuanto tal» 63. Y esa es "la dinámica del proyecto", pues "la constitución del recurso desde el evento es algo fundamental en el dinamismo de la sui$d a d "$, hasta que llegue el momento cuyo único recurso será aceptar lo que ha sido porque no caben ya más posibilidades y ésta es "justamente la hora de su muerte".

La realidad no tiene realidad alguna sino en las cosas reales, pero en las cosas reales "lo real de ellas es justamente la realidad: lo que tienen de realidad". Así, en el hombre, lo que importa ahora no es la antropología, las dimensiones concretas de su vida, sino la persona como realidad: «Es la realidad, ella en sí misma, que se abre a sí misma en forma de suidad, es decir en forma de persona» ${ }^{64}$. Y, en definitiva, no hay más orden transcendental que el de las cosas reales.

Es falso un orden transcendental anterior a las cosas reales, a las que luego se aplicaría, sabido de antemano por el metafísico. Por tanto, la Metafísica general no existe, pues no hay más metafísica que la ciencia y el saber del orden transcendental concreto. «Y lo que se llama Metafísica general sería el ver la realidad en tanto que procedente de Dios y de una causa primera. Pero esto es una consideración completamente extramundana» 65 . El dinamismo es la realidad que se constituye, se abre a sí misma y va dando de

61. EDR 233.

62. EDR 235.

63. EDR 239.

64. EDR 243.

65. EDR 244-5. 
sí. La constitución de la realidad es el dinamismo y éste «es uno de los momentos intrínsecamente constituyentes del orden transcendental en cuanto tal» 66 .

\subsection{El dinamismo de la realidad en la convivencia}

Ser persona consiste en hacer la realidad propia. Esta suidad es dinámica y configura la personalidad "como ser de la sustantividad humana". El hombre es ser "con" y ese ser con es intrínseco a su vida. Esta unidad es "el estado constructo de la vida" que le da sentido y posibilidades. Al actualizarlas, el hombre las hace suyas y se las apropia. Así el hombre "es una fluencia": sólo es el mismo no siendo siempre lo mismo. "El hombre no puede ser persona sino personalizándose" y esa personalización es "una rigurosa innovación". «Esta innovación es la libertad. El acto de libertad es una innovación» 67 . La libertad es radical innovación, una cuasi-creación en permanente inquietud que el hombre mismo prepara, es el dinamismo de la suidad desde la "realidad innovante inquieta en ser".

El ser con del hombre es principalmente convivencia con otros hombres. «Y sólo en esta convivencia soy mí mismo en forma concreta. El mí mismo es un mí mismo en convivencia» 68 . La convivencia no es simple interacción, "pertenece a la estructura de cada uno de los hombres". Todo ser viviente está vertido a los otros vivientes, lleva en sí a los demás, "desde sí mismo" en su propio ser y constituye, desde su propia realidad como tal, esa peculiar unidad que llamamos nosotros.

Así es la convivencia en sociedad. Pero la sociedad no tiene sustantividad propia, «es tan sólo un momento de la sustantividad de los individuos. Y como la sustantividad de los individuos es una estructura, hay que decir que la sociedad consiste en un momento estructural de los individuos entre sí. La sociedad no es una sustancia, es una estructura» ${ }^{69}$. Se trata de una habitud, un modo de habérselas con la realidad.

La sociedad es un momento estructural de la sustantividad humana con carácter de habitud que consiste en estar afectado por los demás en tanto que otros, no en tanto que personas pues eso sería "una comunión de personas". La sociedad implica cierta despersonalización y simultáneamente un poder

66. EDR 245

67. EDR 250.

68. EDR 252.

69. EDR 255. 
pues la sociedad como momento estructural y habitudinario de mi propia sustantividad "ejerce un tipo de influencia sobre mí que es justamente un poder" que es el poder del nosotros. Se trata de una comunidad en la realidad que "se ha hecho algo común" y por eso mismo pública. Así, "la sociedad es la estructura de la realidad en común".

Ahora bien, la vida es convivencia pero también un sistema de posibilidades para la vida personal y social. Ese sistema «define la presencia de la sociedad en la vida de cada cual, y las posibilidades de la inserción de cada cual en la vida de la sociedad» 70 . En ese sentido, la sociedad es cuerpo social, "es decir, el sistema de posibilidades sociales" que podemos llamar mundo. Cada persona tiene su mundo y «todos los de una sociedad, en un momento determinado, tienen el mismo mundo» ${ }^{71}$, forman un cuerpo social. La historia es precisamente "la actualidad de las posibilidades del cuerpo social en cuanto tal".

El mundo es nuestro topos, un sistema de posibilidades, no mero tópico, encontrado sin hacer nada especial: "uno nace y él está ahí". El mundo es arjé, tyjé y moira, principio, suerte y destino de nuestra vida: «La topicidad del mundo es árquica, es tyjé, tyjánica -si se quiere- y es de moira» ${ }^{72}$. Todo hombre está incorporado al sistema de posibilidades, al mundo, a la historia, como pide Jesús para sus discípulos, lo otro seria una utopía, sin topos, "fuera del mundo" y "de la realidad".

El hombre está incorporado a una tradición dada, tradición que es reactualización "como un sistema de posibilidades". Desde esa tradición el hombre se plantea su aspiración, acepta unas cosas y rechaza otras, e inicia una conspiración con el dinamismo de la historia, de modo que ésta es el producto de la sociedad, y no al revés como cree Hegel. El cuerpo social es "el sujeto formal de la historia".

La historia ni es fluencia ni desarrollo, como afirma Hegel. La historia "no es jamás una prolongación de la evolución" aunque no sea independiente de ella. La historia es "un alumbramiento y una obturación de posibilidades". La evolución y el desarrollo "operan pura y simplemente sobre el concepto de realidad", "el carácter formal y primario del dinamismo histórico es justamente la desrealización", pues la historia carece de mismidad, es una estructura abierta: «La historia está abierta a un tipo de mundo distinto, cosa distinta de una esencia abierta en el sentido abstracto del vocablo» 73 .

70. EDR 259.

71. EDR 260.

72. EDR 263.

73. EDR 270. 
Para Hegel el espíritu subjetivo no está conservado en el espíritu objetivo de la historia "mas que como recuerdo". Esto es terrible. Zubiri busca un sistema intermedio, entre espíritu subjetivo y objetivo, que sería la realidad en cuanto tal en su respectividad dinámica. El dinamismo histórico es el dinamismo de la mundificación. No se trata de un mundo que es todo y se come las personas. Estas "no forman parte del mundo, pero sí están en el mundo". «Lo que pasa es que ese carácter respectivo del mundo, en su dinamismo y en su actividad propiamente mundana en cuanto tal, no transparece y funciona como tal sino justamente en las personas humanas» 74 .

Solamente en ellas "la mundificación significa que el mundo es formal y reduplicativamente mundo". Así acontece la mundificación en cada persona y "la mundificación de la suidad", y esa es la mundificación metafísica "en que consiste la historia". De modo que la historia y la sociedad son para el hombre y no el hombre para la historia y la sociedad.

\subsection{La realidad y su dinamismo como modo de estar en el mundo}

El dinamismo es "un momento estructural de las cosas" por el que "las cosas están en el mundo". Esta forma de estar en el mundo es dinámica.

La realidad es emergente en virtud del dinamismo de lo real. El tiempo es la forma general del dinamismo pues toda realidad emerge en un cuándo y un donde. Para Kant los fenómenos físicos están en el espacio y los mentales están en el tiempo. Zubiri no acepta esto y piensa que el tiempo tiene una estructura topológica.

Elementalmente el tiempo es duración "una especie de línea que dura". Además tiene partes, un antes, un ahora y un después, o pasado, presente y futuro. $\mathrm{Y}$ estas partes están unidas "en forma de continuidad propiamente dicha", pero "el problema de la conciencia de la duración no coincide con el problema real de la estructura del tiempo".

Para unos el tiempo es limitado, para otros es cíclico, infinito, como en los griegos. Para los semitas el tiempo es lineal, cada año empieza de nuevo. Por otra parte el tiempo no sería, para Zubiri, continuidad sino ordenación en sus partes. Pero en cada momento el tiempo es unà realidad fluente-distensio quaedam animi (san Agustín) - y no existe más que el Presente. Así la continuidad, la ordenación y la fluencia componen "la estructura topológica del tiempo". Además el tiempo tiene dirección, una dirección única, irreversible. $\mathrm{Y}$ tiene estructuras métricas de tanto y cuánto tiempo. Del mismo modo, im-

74. EDR 274. 
porta mucho la colocación de las cosas en el tiempo. Además está el kairós, la oportunidad, y la edad. En Aristóteles el tiempo es "la medida del movimiento según el antes y el después". No es un círculo vicioso.

Entonces ¿qué es el tiempo?. El tiempo es el ahora, "un ahora fluente, fluens". Es también el pasado que empuja al presente. Así se entiende la distensio animi de san Agustín y la durée de Bergson. «El tiempo, pues, es esta tensión que muerde en las cosas» 75 . Como presente conserva el pasado que "ha conducido a él". Es también el futuro, el "por venir", lo que "va a venir", "es el tiempo del proyecto, del proyectar", incluso el proyecto de no hacer nada, "sino dejarse transcurrir". El proyectar es una tensión dinámica, una necesidad del hombre. Pero la tensión no es el tiempo.

El tiempo no es fluencia ni cambio sino que es un dar de sí: "Es un dar de sí que requiere tiempo". El tiempo no es una línea dinámica donde están las cosas como el espacio no es el receptáculo que imaginaba la física antigua. «La realidad es espaciosa y es temporal, pero no está en el espacio, ni está en el tiempo como en sitios donde se puedan colocar las cosas. El tiempo es una temporalidad, pero como una respectividad: es el tiempo de unas cosas respecto de otras» 76 .

El tiempo no es fluir ni dar de sí sino estar dando de sí y estar fluyendo. «El dinamismo del dar de sí, o del fluir -como actual en el mundo en cuanto tal-, eso es el ser del dar de sí. Y ahí es donde está el tiempo» 77. Es un estar dando de sí, la actualidad de la realidad en el mundo y por "consiguiente el ser".

El tiempo es "pura actualización", una pura actualidad de lo real en su respectividad, la actualidad del dar de sí en el mundo: "El estar efectivamente dando de sí y en fluencia", pero no es la fluencia ni el dar de sí. El ser no se funda en el tiempo, como en Heidegger, sino el tiempo en el ser. El tiempo es respecto del dinamismo lo que la luz respecto a la luminaria: «El tiempo es la actualidad del ser, aquel estar en la luz de algo que acontece, y que acontece precisamente como momento dinámico de la realidad que es lo que equivaldría justamente a la luminaria. -El tiempo es el ser del dinamismo» 78.

Toda cosa nace y emerge en el tiempo. «Está siendo dada de alta en la realidad, en cierto modo. Y ahí es donde está el tiempo» ${ }^{79}$. El tiempo no es ni el antes ni el después ni el ahora sino su misma unidad. No se trata del algo procesual ni de una absorción de los tres momentos como en Hegel. Es una

75. EDR 291.
76. EDR 293.
77. EDR 295.
78. EDR 296.
79. EDR 297. 
unidad gerundiva, "la esencia del tiempo es el siempre", una cierta estabilidad, cierta "demora en el ser del estar dando de sí".

La actualidad de la dureza de algo en el mundo es la duración. La actualidad en el mundo, en la permanencia del cambio, es perduración no simplemente duración. Pero la eternidad no es perduración. La eternidad «es un modo interno, intrínseco de la Realidad Divina, que vive de una manera plenaria pero no de una manera monolítica, que es cosa distinta» 80 .

Cada proceso físico tiene su tiempo intrínseco y esencial, su propio tiempo y su modo propio de tiempo. El tiempo es una "unidad real": «la unidad del tiempo es la actualidad de la unidad dinámica de la respectividad en el mundo en cuanto tal» 81 . La realidad es tempórea como las cosas son espaciosas. Hay, al menos, tres modos de estar en el tiempo como devenir en otro v. gr. en el amor o estar constituyendo el tiempo, o fluyendo justamente en sí mismo o como contar con el tiempo que es tomarlo como una "estructura sinóptica y no como una estructura fluente".

El hombre proyecta porque aunque es fluyente cuenta con el tiempo. Así el corredor no sólo avanza dando pasos sino que tiene una visión global de su carrera. Por ser inteligente tiene el hombre tiempo con que contar. «Efectivamente, por ser inteligencia sentiente el hombre tiene esa interna unidad metafísica entre el tiempo como fluencia y el tiempo sinóptico de proyectividad. He aquí pura y simplemente el tiempo humano» ${ }^{82}$. Además el hombre puede dar tiempo al tiempo y también puede hacer tiempo, o dedicarse a pasar el tiempo o a perder el tiempo. "Y se puede sobre todo recuperar el tiempo. Ni que decir tiene".

Según los orientales el tiempo es el que cuece todas las cosas y los griegos pensaban que el tiempo es un poder "devorador y destructor". «Personalmente, pienso lo contrario: El tiempo es siempre y solamente un tiempo de plenificación de sí mismo: es justamente estar dando de sí» ${ }^{83}$. Es la realidad caduca la que devora el tiempo y no al revés.

«El tiempo es pura y simplemente la forma mundanal del dinamismo como un dar de sí» ${ }^{84}$. Pero el tiempo no es el dar de sí sino "el estar dando de $s \hat{\imath}$ ". El tiempo no es un modo de realidad sino "de la realidad en su ser" y consiste "en ser dante de sí". Si el ser sustantivo es realitas in essendo, "en este caso el in essendo consiste justamente y formalmente en el tiempo". "El mundo no está en el tiempo, es temporal: es tempóreo". «El tiempo es la ple-

80. EDR 301.

81. EDR 303.

82. EDR 307.

83. EDR 308.

84. EDR 309. 
nificación entitativa de la realidad. Y como tal el dinamismo de la realidad, en tanto que actualidad en el mundo, es temporeidad» 85 .

\section{Conclusión. La realidad en su dinamismo}

Zubiri ha planteado el problema de la realidad dinámica. Según él, la variación afecta a las notas adherentes no constitutivas de la realidad. La alteración es el dinamismo de las notas constitutivas. La transformación es la constitución de nuevas sustantividades. La generación es la constitución de nuevas esencias sustantivas por vía genética. La evolución es "la constitución de nuevas esencias quiddificadas por la integración de las mutaciones en la sustantividad". Generación y evolución pertenecen al "dinamismo de la mismidad". Así: "La vida consiste en poseerse", ser lo mismo no siendo siempre lo mismo.

En las esencias abiertas, en el hombre concretamente, poseerse o."poseer la propia realidad en forma propia" es justamente hacer la realidad "suya" y eso es hacerse persona: «El dinamismo de la suidad no es sino el dinamismo de la personalización» ${ }^{86}$. Este dinamismo se realiza con las cosas y los hombres. "Es la vida como esbozo y apropiación de posibilidades. Es el dinamismo de posibilitación" que con los otros hombres entra en un dinamismo de comunización y forma un "cuerpo social". Ese dinamismo del cuerpo social, de la realidad en común, es lo que constituye la historia, y el mundo en común según el dinamismo de la mundanización.

El mundo es la unidad dinámica que constituyen todas las cosas por su respectividad. La unidad del dinamismo no es la respectividad pero la respectividad funda el dinamismo pues es el fundamento de la actividad de las cosas activas por sí mismas. El dinamismo es un devenir que no es igual al cambio. El dinamismo es además actuación. La actuación es algo intrínseco a las cosas, es algo constitutivo: "la realidad es activa por sí misma". La realidad "de suyo" es un momento de la realidad y el dinamismo "no es sino la esencia misma dando de sí lo que ella constitutivamente es". El dinamismo es un dar de sí.

En este dinamismo acontece la funcionalidad de lo real en tanto que real. Esta funcionalidad es la causalidad: «La causalidad es pura y simplemente la funcionalidad de lo real en tanto que real» ${ }^{87}$. La causalidad afecta al sujeto

85. EDR 310.

86. EDR 312.

87. EDR 317. 
primario del dinamismo que es el mundo. La causalidad reside en el mundo como unidad radical, no en las cosas. Pero el mundo no es una magna res de lo que todo procede. Eso sería hegelianismo. El mundo no es cosa y por tanto no es causa.

Cada realidad, en cuanto respectiva, es un momento del mundo. Esa respectividad y ese dar de sí es lo que llama Zubiri éxtasis que es "la respectividad del dar de sí". «La causalidad es un constitutivo éxtasis precisamente porque es la estructura misma del dar de sí en respectividad»88. Desde el punto de vista de la causa es determinante, desde el punto de vista del efecto es determinado. Eso no significa determinismo. El determinismo es una forma degradada de causalidad y no es esencial a la causalidad. Esta es siempre extática y es tanto más causa cuanto más extática.

Así las personas, aunque condicionadas, ponen los antecedentes ellas mismas y esto es la libertad. Se es tanto más causa cuanto se es más libre. «Y la libertad es la forma suprema de la causalidad, porque es la forma suprema del éxtasis» 89 .

«Si la causalidad es la funcionalidad de lo real en tanto que real, el poder es la dominancia de lo real en tanto que real» $(. .$.$) «El poder es algo que está$ inscrito precisamente en la estructura misma del mundo» 90 .

Ese poder es arjé, principio de las cosas, es además, algo árquico como principio interno y constitutivo, y arcóntico, supremo arconte del Universo, que lo ajusta y lo armoniza: «La unidad intrínseca de esas tres dimensiones es lo que constituye el Poder. Y ese Poder del arjé es justamente aquello que da lugar, según Anaximandro, a las vicisitudes del Universo y con cuya enunciación nació la Filosofía en el mundo. El dinamismo tomado sintéticamente en los dos aspectos, de causalidad y poder, es el poderío causal de la realidad en tanto que realidad» 91 .

\section{El dinamismo de la realidad}

Como ya sea ha dicho el universo es el conjunto de estructuras de las distintas realidades en su respectividad. El mundo no es un orden sino un conjunto de estructuras internas respectivas. La realidad tiene unos dinamismos de variación, de transformación, de generación y evolución según los cuales se desarrolla. Primero se llega al nivel de la vida, al "dinamismo de la mismi-

88. EDR 318.

89. EDR 319.

90. EDR 320.

91. EDR 321 
dad". Luego se pasa de las esencias cerradas a las abiertas, entonces «se inicia la suidad, la comunidad y la mundanidad de lo real» 92 .

Esos dinamismos no solamente se apoyan unos en otros sino que tienen "una estricta unidad metafísica de enorme riqueza" que es capaz de "dar extáticamente de sí". No se trata solamente del paso de la potencia al acto sino de algo mucho más radical donde se "despliega efectivamente la riqueza insondable de lo real en tanto que real". Así se despliega también la potenciación con virtualidades nuevas en la evolución, es como una cuasi-creación. La vida desarrolla el dinamismo de la potenciación o posibilitación "en la que produce lo posible antes que lo real".

El dar de sí desarrolla una verdadera innovación: «El mundo, gracias a su dinamismo está en constante innovación. En constitutiva innovación» ${ }^{93}$. Y la realidad "va entrando dentro de sí misma en forma de mismidad". Luego se va "abriendo a sí misma". Y a fuerza de ser ella misma «termina siendo suya. Es justamente la suidad de la persona» ${ }^{44}$. Finalmente se abre a los demás, "es la realidad constituida en común", en comunidad, se hace sociedad y crea "un mundo distinto para cada uno en épocas distintas de historia".

No se trata de la evolución de un todo hegeliano sino que cada uno de estos pasos solamente acontece en las cosas reales, "en cada uno, y solamente en cada una de las cosas reales". Y así «acontece a la vez en millones de cosas reales. Millones de seres vivos, millones de personas, millones de formas sociales en las que ciertamente acontece lo que aquí acabo de exponer» 95.

Todo esto acontece también en el tiempo, siendo tempóreamente en el mundo, en "la realidad dando de sí en tanto que realidad". Se trata de una verdadera unidad dinámica en la que cada realidad superior "se va montando sobre el substratum de una realidad de orden inferior". Siempre se trata de estructuras no de sustancias, pues la realidad del mundo "es sustantividad y estructura, pero no es sustancia".

Así esta realidad, activa y dinámica, a medida que va dando más de sí "va siendo cada vez más realidad". No se trata de que sea más perfecta sino de que sea más realidad. "Sin duda, es más imperfecta la realidad de un viejo que la de un hombre maduro, pero es más realidad. Esto no lo olvidemos. Se tiene en la vida cada vez más realidad". La realidad, por ser activa, cada vez es más realidad según va dando de sí, pero este dar de sí tiene justamente un límite. «Este límite es la intrínseca caducidad dinámica de lo real en tanto que real» ${ }^{96}$.

92. EDR 323.

93. EDR 324.

94. EDR 325.

95. EDR 326.

96. EDR 327. 
Por tanto, los dinamismos del mundo constituyen una "unidad interna", intrínseca, polivalente. «Una realidad que comienza por estar y no hace más que variar, que entra en sí justamente haciéndose misma; que a fuerza de ser misma se abre a la suidad, que se estatuye en forma de comunidad y se estructura en forma de un mundo. Hasta un cierto momento y un cierto límite solamente, porque la realidad es caduca, porque tiene un límite en su propia realidad. -Esta es la estructura dinámica de la realidad» ${ }^{97}$.

En definitiva, insiste y sentencia Zubiri: Es "absolutamente quimérico" afirmar que su lectura de realidad sea una teoría estática o meramente conceptual, pues estamos ante una estructura "cuyos ingredientes de constitución son activos y dinámicos por sí mismos". El dinamismo y el dar de sí «compete esencial y formalmente a la esencia tal como la he descrito en mi modesto y pesado libro Sobre la esencia» ${ }^{98}$.

\author{
D. Natal Álvarez \\ Estudio Teológico Agustiniano \\ Valladolid
}

97. EDR 327.

98. EDR 328. Cfr. LAín ENTRALGo, P. Qué es el hombre. Evolución y sentido de la vida. Oviedo 1999, 29-67. 